\title{
Algumas Considerações Sobre o Fazer Científico Realizadas a Partir da Análise dos Modelos de Ciência Propostos por Taylor, Wundt e Watson
}

Vvvvvvvaeaeaeaeddddddddaeaeaeaeeeeee eeeeeeeeeeeaeeeeeeeeeeeeeeeeeeee ddddddddddddddddddddddddddddddddeeeaeeae

Resumo: A história das ciências como um todo, incluindo a história das ciências humanas e, particularmente, a história da Psicologia, nos presenteia com exemplos de como às vezes o fazer científico é restringido aos lugares comuns da metodologia. Dessa forma, o objetivo deste artigo é refletir sobre a crença de que a ciência é o próprio método que ela utiliza, demonstrando que metodologias particulares decorrem da adoção de determinados pressupostos filosóficos também particulares, que podem levar o fazer científico a algumas incorreções, nem sempre refutáveis por questões de lógica.

Palavras-Chave: Ciência, Filosofia, metodologia.

Abstract: Science history as a whole, including the history of the human sciences and particularly Psychology history, offers good exemples of how scientific development can be inserted in the common place of methodology. Thus, the main goal of this article is to reflect about the belief that science itself is the proper method used. It shows that specific methodologies result from the acceptance of certain philosophical statements, also espefic, which can cause some inaccuracy to scientific development, not always refutable by logics matters.

Key Words: Science, Philosophy, methodology.

Alvarenga Ribeiro

Psicólogo formado pela UEMG, campus de

Divinópolis, e pósgraduando em Liderança e Gestão de

Pessoas pela FADOM (Faculdades Unificadas do Oeste de Minas).
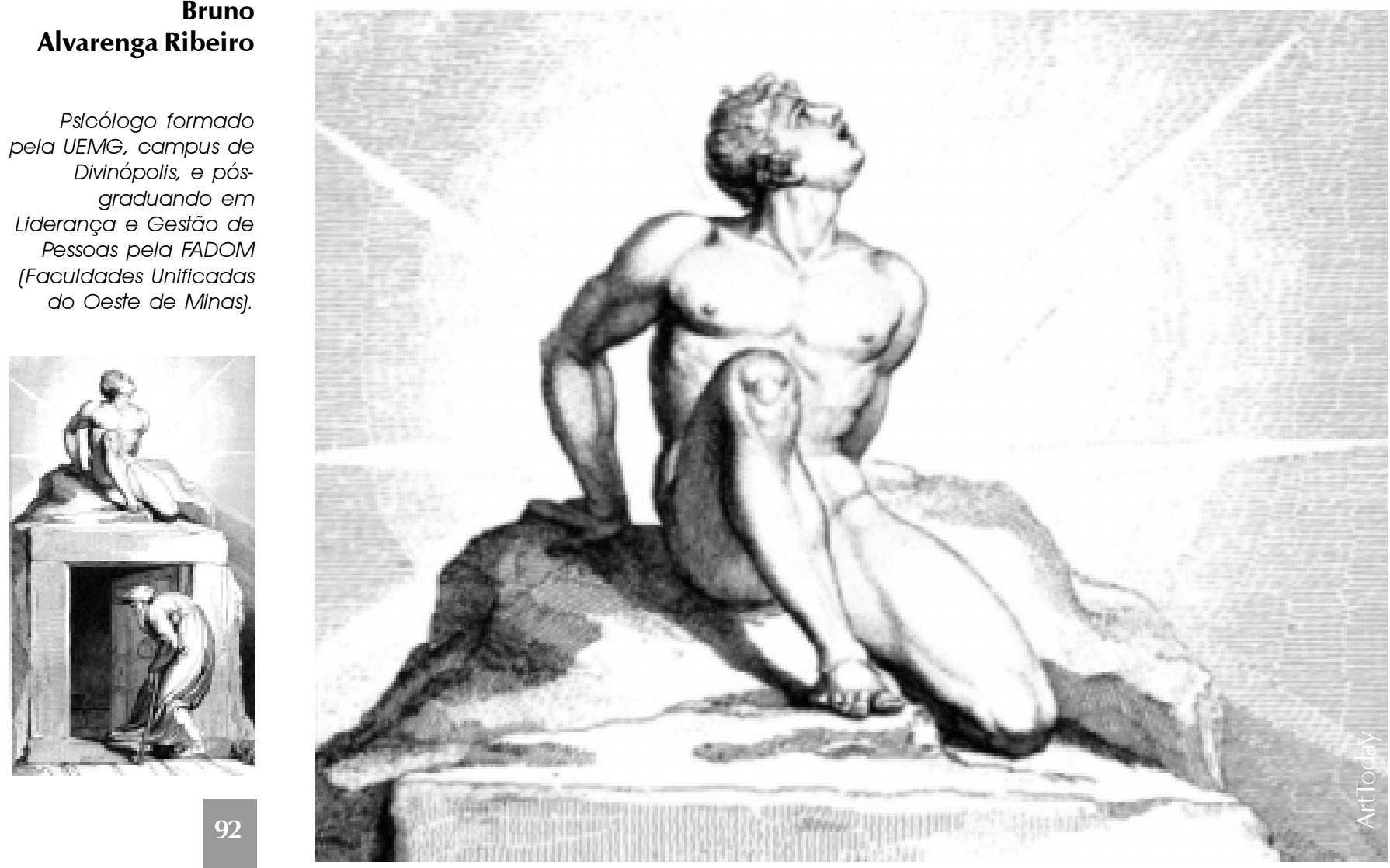
"Os instrumentos nos dão um quadro empolgante da ciência em ação, mas, embora a ciência não pudesse ter ido muito longe sem os aparelhos que aperfeiçoam nosso contato com o mundo, e nenhuma ciência avançada fique desamparada sem eles, os aparelhos não são a própria ciência. Não devemos nos perturbar se os instrumentos familiares ainda estiverem faltando em um novo campo, nem deve a ciência ser identificada com a medida exata, com o cálculo matemático. É preferível ser exato a ser inexato, e muito da ciência moderna seria impossível sem observações quantitativas e sem os instrumentos matemáticos necessários para transformar os dados em proposições mais gerais, mas podemos medir ou usar matemática sem nenhum modo científico, tanto quanto podemos ser científicos, de um modo elementar, sem esses recursos" (Skinner, 1998: 12).

O objetivo deste trabalho, como ressaltado no resumo que o abre, é realizar uma reflexão sobre o fazer científico em sua relação inseparável com a Filosofia. Para isso, diversos pensadores provenientes de diferentes áreas do saber foram consultados, não com o intuito de fazer uma miscelânea de pensamentos, e, sim, de construir um quadro argumentativo em que as partes não sejam auto-excludentes e, acima de tudo, que contribua para uma discussão que não insira a ciência ao lugar comum da metodologia. Ainda que alguns autores consultados não tenham jamais tido algum diálogo, isso não quer dizer que não possamos realizá-lo em prol da discussão proposta, pois, afinal de contas, todos, de alguma forma, já refletiram sobre a problemática questão que agora passamos a analisar.

Há algum tempo, tem-me intrigado a persistência da crença, no meio universitário, de que a pesquisa científica se resume aos lugares comuns da metodologia. Por esse motivo, ela parece tão distante do estudante universitário que não pode contar com uma aparelhagem de ponta, devido à não existência, em nosso país, de uma tradição de investimento no empreendimento científico, o que, aliás, constitui um problema de gerenciamento comportamental. No entanto, isso seria assunto para outro artigo ou até mesmo para uma pesquisa mais aprofundada, que não necessitaria de métodos de mensuração altamente precisos para ser realizada, pois não é a mensuração a marca da ciência, mas, sim, a descrição de relações entre eventos naturais.

Uma conseqüência direta dessa crença no domínio das ciências humanas é a suposição de que é necessário desenvolver métodos especiais para o estudo de seus objetos, dadas as suas complexidades e suas outras naturezas diferentes da(s) natureza(s) do(s) objeto(s) de estudos das ciências naturais, como se houvesse uma descontinuidade no mundo dos fenômenos da natureza, além de supor a ausência de determinação para a ocorrência dos eventos estudados pelas ciências do homem, pois estes podem, no máximo, ser influenciados, mas jamais determinados. Na verdade, o termo influência parece suavizar o problema de se prever o que fará o objeto das ciências do homem, seja ele qual for, colocando ordem onde anteriormente parecia reinar o caos. Dessa forma, torna-se possível a consecução de uma metodologia que mantenha a crença de que a ciência é o próprio método que ela utiliza, enquanto o contrário é que deveria ser verdadeiro: "A metodologia não impõe uma definição de ciência; ao invés, decorre dela" ${ }^{1}$.

Ao que tudo indica, a persistência da crença à qual me refiro e seus desdobramentos tem origem em uma carência filosófica. Esta impede o estudante de identificar que, por trás do método, existe um conjunto de proposições epistemológicas que o sustentam e tornam possível a sua viabilização, e a história das ciências como um todo - incluindo as ciências humanas e particularmente a história da Psicologia - nos oferece exemplos de como certas confusões metodológicas se acham ancoradas em determinadas concepções filosóficas acerca da construção do conhecimento científico.

Taylor, Wundt e Watson são bons exemplos de como certas metodologias particulares decorrem de uma definição de ciência também particular. Todos os três autores se preocuparam em abordar seus domínios de estudo com uma metodologia que garantisse a realização de seus objetivos e fosse, ao mesmo tempo, fiel às suas concepções de ciência, levando-os ao reducionismo metodológico de seus objetos.

Com formação em Engenharia, Taylor pensou ser capaz de colocar ordem no caos em que se encontravam as indústrias, no início do século XX. Aplicou ao âmbito empresarial a metodologia científica derivada dos conhecimentos das ciências exatas, com o objetivo de aumentar a eficiência organizacional. Dotado de uma folha de registros e um cronômetro, Taylor calculou o tempo que um operário gastava para realizar determinado desempenho. Registrado o tempo, eliminou os movimentos desnecessários, prescrevendo o essencialmente necessário a ser realizado por um trabalhador para que seu labor fosse produtivo. Dessa forma, Taylor pensou estar exercendo uma administração científica em substituição a uma administração empírica, simplesmente aplicando uma série de cálculos ao desempenho de um operário, cálculos esses que, em última instância, possibilitaram a formulação de princípios padronizados aplicáveis no controle de operações fabris. Não obstante, os princípios de administração
1 - Starling, R. 2001, p. 4 


\author{
"Qualquer idéia que \\ nos permita novegar, \\ por assim dizer \\ qualquer idéia que \\ nos transporte com \\ vantagem de \\ qualquer parte de \\ nossa experiência a \\ qualquer outra, \\ ligando as coisas \\ satisfatoriamente, \\ operando com \\ segurança, \\ simplificando \\ economizando \\ trabalho é \\ verdadeira só por \\ isso, é verdadeira \\ nessa medida, é \\ instrumentalmente \\ (itálico original) \\ verdadeira"
}

William James

2 - Para uma crítica do privilégio do princípio da abstração, ver Politzer:

3-Matos, M. A. 1999, p. 191.

4 - A esse respeito, ver Politzer

5 - Para uma discussão mais aprofundada da refutabilidade e irrefutabilidade de uma idéia, ver Sokal e Bricmont. Os autores ainda discutem o que distingue a ciência de outros discursos acerca da realidade, fornecendo uma resposta matizada - como eles mesmo fazem questão de assinalar-sobre essa distinção.

6-William James apud: BAUM, W. M. Compreender o Behaviorismo: $\quad$ Ciência Comportamento e Cultura, p. 38 científica de Taylor constituem uma metodologia ingênua, em primeiro lugar, porque a mensuração de um desempenho não garante a construção de princípios preditivos generalizáveis, pois a mensuração pela mensuração não especifica que eventos se alteram (variável dependente) pela modificação de outros eventos (variável independente) relacionados aos primeiros, e, em segundo lugar, porque é uma metodologia baseada em princípios filosóficos ingênuos sobre um modelo de homem vadio e negligente, que precisa ser disciplinado, modelo que ficou conhecido historicamente como "Homo Economicus". Portanto, ao não se importar com o porquê de um operário desempenhar uma função de uma forma e não de outra - pois seu modelo de homem (altamente abstrato) fornecia as explicações necessárias -, e ao se basear em uma concepção filosófica de ciência, fundamentada na mensuração pela mensuração, Taylor negligenciou variáveis importantes do processo fabril, além de reduzir as que teve acesso a abstrações apriorísticas que estão longe de ser validadas empiricamente, ou seja, não demonstrou como as variáveis que dizia estar "administrando" se alteravam em função da modificação de outras a elas relacionadas, o que impossibilita uma aprovação pública do conhecimento produzido, possível somente na medida em que fosse especificada a relação entre essas variáveis e a condição em que a relação ocorre, entendendo que as mesmas variáveis devam ser dotadas de dimensões físicas e temporais.

Considerado o fundador da Psicologia Experimental, Wundt "propôs que fosse considerada apenas a experiência pura, descontaminada de interpretações e reflexões pessoais. Para tanto, o sujeito deveria ser treinado cuidadosamente a concentrar-se na tarefa e atentar somente para o estímulo em pauta, não para suas outras dimensões; deveria estar isolado de quaisquer outras estimulações e distrações; deveria responder imediatamente ao estímulo, sem pensar e sem se valer de sua história passada; deveria responder não ao objeto e a seu significado e sim à própria sensação; deveria distinguir entre sua experiência imediata e sua experiência elaborada..." ${ }^{3}$ Depreende-se daí uma ênfase no método, nos procedimentos de treinamento que possibilitassem o acesso da experiência pura sem contaminação e da vida mental determinada por condições fisiológicas. Com Wundt, os aparelhos dos laboratórios de Fisiologia migram para os de Psicologia ${ }^{4}$, pois era preciso saber quais seriam os processos fisiológicos que determinavam os elementos da vida mental, impossíveis de serem conhecidos somente via introspecção, considerada por ele um método. No entanto, a ênfase em uma metodologia específica não é casual, pois é sustentada por princípios filosóficos sobre aquilo que seria o objeto de estudos da Psicologia: a experiência imediata e a ligação entre o corpo e a mente, ligação que Wundt chamou de "Unidade Psicofísica".

Antes de passarmos à análise dos pressupostos sustentados por Watson, vale abrir um pequeno parêntesis para esclarecermos a discussão realizada até aqui sobre ciência e Filosofia via crítica dos fazeres "científicos" de Taylor e Wundt. O objetivo foi demonstrar que qualquer projeto de ciência, seja ele qual for, não se faz sem Filosofia, e que, por mais ingênuo que possa parecer, seja por identificar o fazer científico com a mera utilização de uma metodologia técnica - tomada de empréstimo a um corpo de conhecimentos com o status de objetivo, como é o caso das ciências exatas -, ou por realizar descrições e observações objetivas, pretendendo que não sejam contaminadas por quaisquer eventos inesperados, o projeto estará fundamentado em argumentos filosóficos que, dotados de uma lógica, tornam-no possível, ainda que considerado ingênuo pelos motivos acima mencionados.

Se, por um lado, a Filosofia ou, melhor dizendo, a adoção de determinados pressupostos filosóficos podem conduzir o fazer científico a algumas incorreções, nem sempre refutáveis por questões de lógica, por outro lado a ciência sem Filosofia é estéril e incapaz de se auto-regular. Não obstante, o fato de uma incorreção - que pode ser uma idéia ou um axioma que leva a um modo de operar sobre o mundo (dos eventos naturais, com dimensões físicas e temporais, sendo esse o campo da ciência) - parecer irrefutável não quer dizer que seja verdadeira ${ }^{5}$. A sua verdade decorre de sua adequabilidade prática, lembrando que não existe uma ordem imanente ao mundo natural, ordem essa que está tão somente nas asserções que dele fazemos e não necessariamente nele (Starling, 2001). William James assim coloca a questão da verdade das asserções que fazemos sobre o mundo:

"Qualquer idéia que nos permita navegar, por assim dizer; qualquer idéia que nos transporte com vantagem de qualquer parte de nossa experiência a qualquer outra, ligando as coisas satisfatoriamente, operando com segurança, simplificando, economizando trabalho é verdadeira só por isso, é verdadeira nessa medida, é instrumentalmente (itálico original) verdadeira"'

O que há no mundo natural são eventos que se relacionam, interagem. A presença de um evento mais aumentará a probabilidade de ocorrência de outro(s) quanto mais houver entre eles uma relação de dependência. Os conceitos criados por nós se encarregam de descrever essas relações, e 
somente por isso a ordem é encontrada no discurso e não necessariamente nos fenômenos estudados mas, se esses são relações entre eventos naturais, que quando descritas têm especificadas as condições que thes deram origem (e origem a própria descrição), o conhecimento produzido pode ser submetido à aprovação pública. Em outras palavras, as condições que deram origem à descrição podem ser reproduzidas, colocando à prova a sua adequabilidade prática ${ }^{7}$. Quando colocada à prova, saberemos se permiti-nos, como afirmou James, transportar-nos de uma parte de nossa experiência a qualquer outra. No entanto, não só seremos transportados de uma experiência a outra, no sentido de lidarmos bem com determinados fenômenos enquanto ocorrem, como também poderemos antever a ocorrência futura de outros, tão somente porque poderemos provocá-los:

"A ciência não só descreve, ela prevê. Trata não só do passado, mas também do futuro. Nem é previsão sua última palavra: desde que as condições relevantes possam ser alteradas, ou de algum modo controladas, o futuro pode ser manipulado" ${ }^{8}$.

A afirmação de que a ordem está no discurso, portanto, não nos permite passar à conclusão de que não existe determinação, pois no universo natural sempre encontraremos relações de dependência entre eventos de dimensões materiais e temporais, e ainda que essas relações sejam complexas e alguns eventos não sejam diretamente acessíveis - como é o caso do estudo do comportamento -, não poderemos substituí-las por relações de influência, seja lá o que isso quer dizer, na tentativa de sermos prudentes. Uma observação: aprovação pública quer dizer ser validado por uma determinada comunidade científica que esteja em condições de reproduzir determinadas relações entre eventos naturais, desde que possua os meios necessários, em parte fornecidos pela descrição da relação; aprovação pública não é, portanto, sinônimo de verdade por concordância, critério defendido por Comte, que estabelece a diferença entre o que é e o que não é ciência. Em Watson, teremos a oportunidade de ver, dentro em breve, os reflexos do critério de verdade por concordância, que o levam a uma posição estritamente metodológica.

A vantagem de transitarmos no mundo dos fenômenos naturais sem supormos a existência de outros mundos é a de que, encontrando certas relações de dependência entre eventos naturais, reproduzíveis segundo os critérios já mencionados, podemos desenvolver tecnologias que nos permitam nele melhor operar. Além de não nos darmos ao luxo de crer que o empreendimento científico é mera construção social, ainda que haja um contínuo entre a atividade científica e a atividade do dia-a-dia que, é claro, não pode ser levado muito longe, pois a ciência realiza suas operações por um caminho mais cuidadoso e sistemático (SOKAL e BRICMONT, 1999).

“...os resultados científicos são amiúde muito mais precisos que as observações cotidianas; eles permitem descobrir fenômenos até então desconhecidos e entram freqüentemente em conflito com o 'senso comum'. O conflito, porém, situa-se no plano das conclusões e não no da abordagem básica" ${ }^{\prime 9}$.

De modo não muito diferente, Skinner, assim coloca a questão:

"A ciência é, certamente, mais do que um conjunto de atitudes. É a busca da ordem, da uniformidade, de relações ordenadas entre os eventos da natureza. Começa, como todos nós começamos, por observar episódios singulares, mas rapidamente avança para a regra geral, para a lei científica. Algo muito parecido com a ordem expressa em uma lei científica aparece em nosso comportamento desde tenra idade. Aprendemos geometria rudimentar do espaço no qual nos movemos. Aprendemos as 'leis do movimento' à medida que nos movimentamos, puxando, empurrando, atirando e apanhando objetos. Se não pudéssemos encontrar certa uniformidade no mundo, nossa conduta permaneceria casual, desordenada e ineficaz. A ciência aponta e complementa essa experiência ao demonstrar cada vez mais relações entre os acontecimentos e ao demonstrá-las cada vez mais precisamente (itálicos acrescentados)" ${ }^{\prime 10}$.

Em última instância, o trânsito no mundo natural é vantajoso por nos permitir avançar do simples para o complexo, lançando mão dos benefícios advindos da simplificação de condições corriqueiras do nosso dia-a-dia, em situações experimentais de laboratório, onde podemos deliberadamente manipular variáveis e estabelecer empiricamente aquelas que são relevantes para o estudo de determinado assunto pois, não havendo uma ruptura na continuidade da natureza, o mundo encontrado no laboratório inevitavelmente será o mesmo encontrado fora dele:

“Para o leigo, o laboratório de pesquisa aparenta, muitas vezes, artificialidade suficiente para permitir a suposição de que ele nada tem em comum com a vida real: é como se os mundos dentro e fora do laboratório fossem dois mundos distintos. Nada mais enganoso. $\mathrm{O}$ mundo existente dentro de um laboratório é parte de um todo, de uma única realidade que apenas na aparência difere do que se passa do lado de fora. Sem qualquer exceção, os princípios que regem os fenômenos ali
"A ciência é, certamente, mais do que um conjunto de atitudes. É a busca da ordem, da uniformidade, de relações ordenadas entre os eventos da natureza".

Skinner

7 - Ver Starling, que apresentou excelente dissertação sobre essa questão

8-Skinner, B. F. 1998, p. 7.

9 - Sokal, A; Bricmont, J. 1999, p. 65. 
estudados são os mesmos que regem a realidade cotidiana. Se assim não fosse, nosso conhecimento sobre física não teria evoluído tanto com a maçã que caiu sobre a cabeça de Newton, ou com a água que transbordou da banheira de Arquimedes. Por serem parte de uma única e indivisível realidades, os mundos dentro e fora do laboratório estão continuamente se alimentando na busca do conhecimento $^{\prime 11}$.

Voltemos um instante a Watson. Talvez a sua grande contribuição seja ter reconhecido que a Psicologia poderia ser uma ciência natural e que seu objeto de estudo era tão determinado por agentes físicos como os objetos das ciências naturais. Claro que haveria de acreditar na determinação, pois tendo sido influenciado pelo Positivismo, equacionou o fazer científico com a busca pela mensuração de causas observáveis para efeitos também observáveis, sendo que as causas antecediam e provocavam os efeitos. Esse modelo de causalidade é uma herança do mecanicismo, paradigma que se mostrou e ainda se mostra eficaz no tratamento de alguns fenômenos no âmbito da Física, mas não para a explicação do comportamento, como bem demonstrou Skinner. Foge às pretensões deste artigo, porém discutir o modelo de causalidade adotado por Skinner.

Quando estabeleceu que o objeto de estudo da Psicologia era o comportamento observável, Watson revelou que o seu Behaviorismo - que mais tarde recebeu o nome de Metodológico, dado por Skinner - considerava importante o critério de verdade por consenso, em que uma verdade só receberia status de científica se pudesse ser observada por diferentes observadores. O comportamento observável, ao contrário da mente, era mensurável, ou seja, era abordável pelos métodos das ciências naturais. Vejam, portanto, que Watson não negava a existência da mente, e só não a considerava como agente causal porque possuía uma substância distinta e inabordável por métodos naturais e objetivos. Dessa forma, equaciona o interno ao mental, recusando qualquer pretensão de estudar eventos que possuíssem a característica de privados, o que o leva a banir da Psicologia a subjetividade, diferentemente do Behaviorismo Radical Skinneriano, que considera importantes os eventos que se passam sob a pele, tão físicos quanto os

10 - Skinner, B. F. 1998, p. 14.

11 -Hünziker, M.H.L. 1999, p.314.

12 - Ver Sokal e Bricmont.

13 - Starling, R. 2001, p. 5

$$
\text { eventos externos ao organismo. }
$$

Como conseqüência da adoção de determinados pressupostos filosóficos que definem o que seria o objeto da Psicologia, Watson é levado a assumir uma postura inteiramente metodológica diante desse objeto, não muito diferente dos dois outros autores mencionados, que reduziram o fazer científico aos lugares comuns da metodologia. Um parêntesis: Taylor não tinha como objetivo edificar um projeto de Psicologia científica como Wundt e Watson, nem era ele um psicólogo, embora seus princípios tenham influenciado largamente o trabalho de muitos psicólogos que atuaram e atuam no contexto organizacional. Suas pretensões eram outras: aumentar a eficiência das empresas através de uma administração "científica" em substituição a uma administração empírica e sem qualquer sistematização, e só tendo sido citado para ilustrar o que não deve ser feito ao tentarmos ser científicos.

Gostaria, neste momento, de retornar à idéia de que a ciência não é mera construção social, simplesmente mencionada sem maiores considerações alguns parágrafos atrás. Essa proposição (de que a ciência é uma construção social) tem raízes bem fecundas e implicações interessantes. É utilizada em favor do argumento de que não podemos conhecer o mundo, e tudo que sabemos sobre ele são convenções arbitrárias. Claro que o mundo não é tão didático quanto nossas teorias. Os fenômenos que nele ocorrem não aparecem classificáveis como em nossas descrições, pois são contínuos e dificilmente discerníveis sem os meios necessários para apreendê-los e torná-los arranjos teóricos. Entretanto, isso não justifica os dizeres de que teorias são convenções que nada dizem sobre o mundo em que vivemos, pois existem princípios estabelecidos durante alguns séculos de pesquisa científica que garantem certa confiabilidade às nossas predições ${ }^{12}$, ainda que sejam fruto de invenções conceituais. Todavia, nossas invenções conceituais podem ser submetidas a aprovação, desde que nunca abandonemos o universo natural. Analisemos o seguinte exemplo:

“(...) força da gravidade não existe. É somente mais uma declaração sobre o mundo. O que existe é o fato de que um objeto inanimado, deixado sem sustentação num campo gravitacional positivo, desloca-se no espaço e no tempo numa certa direção e não em qualquer outra. 'Força da Gravidade' é um conceito, uma declaração verbal que Isaac Newton inventou para falar sobre essa relação e que tem sido aceita porque, quando a utilizamos, aumentamos a previsibilidade e o controle que podemos ter sobre esse fenômeno" ${ }^{13}$.

Sem mais delongas, permitam-me concluir, outra vez citando Starling em uma passagem que penso resumir perfeitamente tudo que foi dito neste artigo: "Numa bela metáfora budista, o que o grande homem fala é o dedo apontado para a lua. Encantar-se na contemplação do dedo é perder a própria lua". Analogicamente, diríamos: contemplar a metodologia é perder a dimensão do fazer científico. 
BAUM, W. M. Compreendero behaviorismo: ciência, comportamento e cultura. Porto Alegre: Artes Médicas, 1999

HÜNZIKER, M. H. L. O mundo dentro e fora do laboratório: duasfaces de uma mesma realidade. In: BANACO, R. A. (Org.). Sobre comportamento e cognição: aspectos teóricos, metodológicos e de formação em análise do comportamento e terapia cognitivista. 2. ed. rev. Santo André: Arbytes, 1999. p. 314-321.

MATOS, M. A. Introspecção: método ou objeto de estudo para a análise do comportamento? In: Roberto Alves BANACO, R. A. (Org.). Sobre comportamento e cognição: aspectos teóricos, metodológicos e de formação em análise do comportamento e terapia cognitivista. 2. ed. rev. Santo André: Arbytes, 1999. p. 188-198.

MATOS, M. A. (1998). Behaviorismo metodológico e behaviorismo radical. In: RANGE, B. (Org.). Psicoterapia comportamental e cognitiva: pesquisa, prática, aplicações e problemas. Campinas: Editorial Psy, 1998. p. 27-34.

POLITZER, G. Crítica dos fundamentos da psicologia I. Portugal: Presença, 1975.

SKINNER, B. F. Ciência e comportamento humano. 10. ed. São Paulo: Martins Fontes, 1998.

SOKAL, A.; BRICMONT, J. Imposturas intelectuais: o abuso da ciência pelos filósofos pós-modernos. São Paulo: Record, 1999.

STARLING, R. Breves considerações sobre ciência, teorias e fenômenos. Boletim Informativo da Associação Brasileira de Psicoterapia e Medicina Comportamental, n. 23, p. 4-5, 2001. 